\title{
Pengaruh Bokashi Terhadap Produksi Cabai Rawit (Capsicum annuum)
}

\author{
Ahmad Raksun ${ }^{1}$, I Gde Mertha ${ }^{1}$ \\ ${ }^{1}$ Dosen Program Studi Pendidikan Biologi FKIP UNRAM \\ Ahmad.raksun@gmail.com
}

\begin{abstract}
Abstrak
Penelitian ini telah dilakanakan di Desa Montong Are Lombok Barat. Penelitian bertujuan untuk mengetahui: (1) pengaruh bokashi terhadap produksi cabai rawit pada lahan pertanian Desa Montong Are, (2) kadar optimum bokashi yang harus diberikan pada lahan pertanian Desa Montong Are agar cabai rawit dapat berprokduksi secara optimal. Dalam penelitian ini digunakan rancangan acak lengkap dengan lima ulangan. Data dianalisis dengan analisis sidik ragam dan uji lanjut dengan Uji Beda Nyata Terkecil (BNT). Hasil penelitian menunjukkan bahwa (1) pemberian bokashi berpengaruh signifikan terhadap produksi cabai rawit (2) kadar optimum bokashi yang perlu diberikan pada lahan pertanian Desa Montong Are agar cabai rawit berproduksi secara optimal adalah $1,0 \mathrm{~kg}$ untuk setiap $10 \mathrm{~kg}$ tanah.
\end{abstract}

Kata-kata kunci: bokashi, produksi, cabai rawit

\begin{abstract}
This research has done in Montong Are Village West Lombok. The aim of this research are: (1) to identify the effect of bokasi on the production of small chili, (2) to identify the optimum extent of bokasi that must be added to the parm land in oder that small chili can product optimally. Complately randomized design with five replicates were used in this research. Data analysis with Anova and least significant differens (LSD).The result of this research are: (1) the application of bokasi has significant effect on the production of small chili, (2) the optimum extent of bokasi that must be given to the soil in order the small chili can production optimally is $1,0 \mathrm{~kg}$ bokasi/10 kg soil.
\end{abstract}

Key words: Bokasi, production, small chili 


\section{PENDAHULUAN}

Bokashi adalah pupuk kompos yang dihasilkan dari proses fermentasi atau peragian bahan organik dengan teknologi EM4 (Effective Microorganisms 4). Keunggulan penggunaan teknologi EM4 adalah pupuk organik (kompos) dapat dihasilkan dalam waktu yang relatif singkat dibandingkan dengan cara konvensional. EM4 sendiri mengandung Azotobacter sp., Lactobacillus sp., ragi, bakteri fotosintetik dan jamur pengurai selulosa (Teruo, 1999).

Berbagai hasil penelitian menunjukkan bahwa pemberian berbagai jenis bokashi memberikan pengaruh yang sangat nyata terhadap pertumbuhan dan hasil jagung manis, pemberian bokashi daun Johar memberikan hasil yang lebih baik terhadap pertumbuhan jagung manis, sedangkan pemberia bokashi daun Gamal memberikan hasil yang lebih baik terhadap produksi jagung manis (Mulyanti dkk, 2015). Aplikasi bokashi berpengaruh pada pertumbuhan vegetatif dan produksi rumput gajah. Bokashi 30 ton per hektar memberikan pertumbuhan vegetatif dan produksi rumput gajah tertinggi (Kusuma, 2013). Pemupukan bokashi dengan dosis 20 ton per hektar memberikan bobot gabah kering per hektar tertinggi (4,70 ton), jumlah anakan produktif tertinggi $(25,00)$ dicapai varietas cianjur (Mulyana dkk, 2011). Pemberian pupuk bokashi Eceng Gondok menunjukkan respon sangat nyata pada total produksi kedelai per plot (Hasibuan dkk, 2017)
Berdasarkan uraian di atas maka peneliti telah melakukan penelitian tentang pengaruh bokashi terhadap produksi cabai rawit di Desa Montong Are Kabupaten Lombok Barat Propinsi Nusa Tenggara Barat. Adapun tujuan penelitian tersebut adalah untuk mengetahui (1) pengaruh pemberian bokashi terhadap produksi cabai rawit pada lahan pertanian di Desa Montong Are, (2) kadar optimum bokashi yang harus diberikan pada lahan pertanian Desa Montong Are agar cabai rawit dapat berprokduksi secara optimal

\section{BAHAN DAN METODE}

Bahan-bahan yang digunakan dalam penelitian ini adalah tanah sawah sebagai media tanam, benih cabai rawit dan kertas label. Sedangkan alat-alat yang digunakan adalah pot plastik, timbangan, parang, alat tulis menulis, cangkul, sekop, ember plastik dan gunting. Media tanam yang digunakan adalah tanah sawah yang diambil dari lahan pertanian Desa Montong Are Lombok Barat. Dalam penelitian ini digunakan rancangan acak lengkap dengan lima ulangan Penggunaan bokashi terdiri atas 8 level yaitu: $\mathrm{B}_{\mathrm{o}}=$ tanpa pemberian bokashi (kontrol), $\mathrm{B}_{1}=$ pemberian $0,2 \mathrm{~kg}$ bokashi $/ 10 \mathrm{~kg}$ tanah $\mathrm{B}_{2}$ = pemberian $0,4 \mathrm{~kg}$ bokashi $/ 10 \mathrm{~kg}$ tanah $\mathrm{B}_{3}=$ pemberian $0,6 \mathrm{~kg}$ bokashi $/ 10 \mathrm{~kg}$ tanah $\mathrm{B}_{4}=$ pemberian $0,8 \mathrm{~kg}$ bokashi $/ 10$ $\mathrm{kg}$ tanah $\mathrm{B}_{5}=$ pemberian $1,0 \mathrm{~kg}$ bokashi/10 $\mathrm{kg}$ tanah $\mathrm{B}_{6}=$ pemberian 1,2 $\mathrm{kg}$ bokashi/10 $\mathrm{kg}$ tanah $\mathrm{B}_{7}=$ pemberian $1,4 \mathrm{~kg}$ bokashi/10 kg tanah (Hanafiah, 1994). 
Panen buah cabai rawit dilakuakan setelah buah cabai rawit matang (berwarna merah) Data kuantitatif parameter produksi yang diukur adalah berat basah buah cabai rawit. Data kuantitatif hasil pengukuran parameter di atas dianalisis dengan analisis sidik ragam dan uji lanjut dengan Uji Beda Nyata Terkecil (Gomez dan Gomez, 1995)

\section{HASIL DAN PEMBAHASAN}

Panen buah cabai rawit pada setiap unit percobaan dilakukan sebanyak 6 kali dengan jarak waktu 6 hari. Rerata hasil pengukuran berat basah buah cabai rawit terdapat pada tabel berikut.

Tabel rerata berat basah buah cabai rawit akibat aplikasi bokashi

\begin{tabular}{|c|c|}
\hline Perlakuan & $\begin{array}{c}\text { Rerata berat basah buah } \\
\text { (gr) }\end{array}$ \\
\hline $\mathrm{B}_{0}$ & 380 \\
\hline $\mathrm{B}_{1}$ & 420 \\
\hline $\mathrm{B}_{2}$ & 480 \\
\hline $\mathrm{B}_{3}$ & 532 \\
\hline $\mathrm{B}_{4}$ & 586 \\
\hline $\mathrm{B}_{5}$ & 638 \\
\hline $\mathrm{B}_{6}$ & 630 \\
\hline $\mathrm{B}_{7}$ & 632 \\
\hline
\end{tabular}

Selanjutnya untuk mengetahui pengaruh pemberian bokashi terhadap berat basah buah cabai rawit maka dilakukan analisis data dengan analisis sidik ragam dan uji lanjut dengan uji beda nyata terkecil (Gomez dan Gomez, 1995). Hasil analisis sidik ragam pengaruh pemberian pupuk organik cair terhadap semua parameter yang diukur menunjukkan bahwa aplikasi bokashi berpengaruh nyata terhadap berat basah buah cabai rawit.

Hasil analisis data menunjukkan bahwa tanaman cabai rawit yang tumbuh pada media tanpa pemberian bokashi memiliki rerata berat basah buah 380 gram. Selanjutnya pada setiap unit percobaan yang diberikan bokashi, rerata berat basah buah meningkat sejalan dengan meningkatnya kadar bokashi yang diberikan. Hasil analisis sidik ragam menunjukkan bahwa aplikasi bokashi pada media tanah berpengaruh nyata terhadap meningkatnya berat basah buah cabai rawit. Hal ini sejalan dengan hasil penelitian yang dilakukan oleh sejumlah peneliti. Pemberian berbagai jenis bokashi memberikan pengaruh yang sangat nyata terhadap pertumbuhan dan hasil jagung manis, pemberian bokashi daun Johar memberikan hasil yang lebih baik terhadap pertumbuhan jagung manis, sedangkan pemberia bokashi daun Gamal memberikan hasil yang lebih baik terhadap produksi jagung manis (Mulyanti dkk, 2015). Pemberian bokashi berpengaruh nyata terhadap pertumbuhan dan produksi tomat pada lahan pertanian Desa Pijot (Raksun dan Santoso, 2010). Pemberian pupuk organik bokashi kotoran sapi dan eceng gondok dapat meningkatkan bobot berangkasan tanaman tomat (Soverda dkk, 2008). Pemupukan bokashi dengan dosis 20 ton per hektar memberikan bobot gabah kering per hektar tertinggi (4,70 ton), jumlah anakan produktif tertinggi $(25,00)$ dicapai varietas cianjur (Mulyana dkk, 2011). Pemberian pupuk 
bokashi Eceng Gondok menunjukkan respon sangat nyata pada total produksi kedelai per plot (Hasibuan dkk, 2017) Pemberian berbagai dosis pupuk organik bokashi berpengaruh nyata terhadap tinggi tanaman kedelai (Simaptupang, 1999). Pemberian bokashi pada lahan pertanian dapat meningkatkan pertumbuhan cabai merah (Raksun, 2009). Aplikasi bokashi berpengaruh pada pertumbuhan vegetatif dan produksi rumput gajah. Bokashi 30 ton per hektar memberikan pertumbuhan vegetatif dan produksi rumput gajah tertinggi (Kusuma, 2013).Media terbaik untuk pertumbuhan semai eboni adalah pupuk organik EM bokashi karena media ini dapat meningkatkan solubilitas dan viabilitas hara dalam tanah dan memberikan pertumbuhan semai eboni yang optimal (Sumiasri dan Setyowati, 2006). Penambahan bokashi dalam dosis 250 g pada media tanah NPK dapat mendukung pertumbuhan cabe var. Inko 99 lebih optimal dengan tinggi tanaman $71,15 \mathrm{~cm}$ dan jumlah cabang produktif 40,75 buah (Gustia, 2009). Kedelai varietas galunggung merespon secara signifikan terhadap kompos limbah kelapa sawit, produksi meningkat secara sigifikan (Darma, 2000). Terdapat interaksi antara pupuk organik bokashi dan pupuk nitrogen terhadap jumlah daun, pemberian pupuk organik bokashi 10 ton per hektar berpengaruh baik terhadap komponen kualitas bunga yaitu mampu menghasilkan tangkai bunga terpanjang dan jumlah kuntum bunga terbanyak (Farida dan Hamdani, 2003). Pemberian pupuk kandang 30 ton/ha yang dikombinasikan dengan kapur 2 ton/ha menghasilkan pertumbuhan tanaman terbaik dengan rataan tinggi tanaman $80,7 \mathrm{~cm}$, jumlah cabang primer 33,4 buah, diameter tajuk 105,7 $\mathrm{cm}$ dan produksi terna 25,2 ton/ha. Hasil tersebut berbeda nyata dengan perlakuan control dengan rataan tinggi tanaman $57,3 \mathrm{~cm}$, jumlah cabang primer 20,9 buah, diameter tajuk $67,4 \mathrm{~cm}$ dan produksi terna 6,1 ton/ha (Burhanuddin dan Nurahmansyah, 2010) Demikian juga Farida dan Hamdani (2003) menyimpulkan, bahwa terdapat interaksi antara pupuk organik bokashi dan pupuk nitrogen terhadap jumlah daun, pemberian pupuk organik bokashi 10 ton/ha berpengaruh baik terhadap komponen kualitas bunga yaitu mampu menghasilkan tangkai bunga terpanjang dan jumlah kuntum bunga terbanyak.

Hasil Uji Beda Nyata Terkecil menunjukkan bahwa, perlakuan $\mathrm{B}_{5}$ (perlakuan 1,0 kg bokashi/10 kg tanah) memberikan hasil yang berbeda nyata dengan $\mathrm{B}_{0} \quad$ (kontrol), namun tidak berbeda nyata dengan perlakuan $\mathrm{B}_{6}$ dan $\mathrm{B}_{7}$. Hasil analisis tersebut menunjukkan bahwa dosis optimum bokashi yang perlu diberikan pada media tanam adalah $1,0 \mathrm{~kg}$ bokashi per $10 \mathrm{~kg}$ media tanah.

\section{KESIMPULAN}

Berdasarkan hasil analisis data dan pembahasan pada penelitian ini maka dapat disimpulkan bahwa: (1) aplikasi bokashi berpengaruh nyata terhadap produksi cabai rawit. (2) Penggunaan dosis bokashi $1,0 \mathrm{~kg}$ per 10 $\mathrm{kg}$ media tanah memberikan hasil yang 
lebih baik dibandingkan perlakuan lainnya.

\section{DAFTAR PUSTAKA}

Raksun, A. 2009. Pemanfaatan Bokashi untuk Meningkatkan Pertumbuhan Cabai Merah (Capsicum frutescens). Biologi Tropis 10 (1): 45 - 49

Rakun, A. dan Santoso D. 2010. Pemanfaatan Bokashi untuk Meningkatkan Pertumbuhan dan Produksi Tomat (Lycopersicum esculentum). Biologi Tropis 11 (1): $44-50$

Burhanuddin dan Nurahmansyah. 2010. Pengaruh pemberian pupuk kandang dan kapur terhadap pertumbuhan dan produksi nilam pada tanah podsolik merah kuning. Bul. Littro. 21 (2): 138 144

Darma,S. 2000. Respon tanaman kedelai terhadap kompos limbah kelapa sawit pada dosis berbeda. Jurnal Budidaya Pertanian. 6 (2): 96 - 104

Farida dan Hamdani, J.S. 2003. Pertumbuhan dan hasil bunga gladiol pada dosis pupuk organik bokashi dan nitrogen yang berbeda. Bionatura. 3(2): 68 - 76

Gomez K.A. dan A.A. Gomez. 1995. Prosedur Statistik Untuk Penelitian Pertanian Edisi Kedua Penerjemah: Endang Syamsudin dan Justika S. Baharsyah. UI Press. Jakarta.

Gustia, H. 2009. Pengaruh pemberian Bokashi Terhadap pertumbuhan dan produksi tanaman cabe var. inko-99. Akta Agrosia Vol. 12(2): $113-123$.

Hanafiah, K.A. 1994. Rancangan Percobaan. Teori dan Aplikasi.
Fakultas Pertanian Universitas Sriwijaya. Palembang.

Hasibuan, S., Mawarni, R., Hendriandri, R. 2017. Respon Pemberian Pupuk Bokashi Ampas Tebu dan Pupuk Bokashi Eceng Gondok terhadap Pertumbuhan dan Produksi Tanaman Kedelai. Bernas 13(2): 59 - 64

Kusuma, M.E. 2013. Pengaruh Pemberian Bokashi terhadap Pertumbuhan Vegetatif dan Produksi Rumput Gajah (Pennisetum purpureum). Ilmu Hewani Tropika 2(2): 40-45

Mulyana, D., Sahidin dan Iqbal, A. 2011. Pengaruh Dosis Bokashi terhadap Pertumbuhan dan Hasil Tiga Varietas Padi. Agrin 15(1): $18-26$

Mulyanti, S.S., Made, U. dan Wahyudi, I. Pengaruh Pemberian Berbagai Jenis Bokashi terhadap Pertumbuhan dan Hasil Jagung Manis (Zea mays Saccarata). Agrotekbis 3(5): 592 - 601

Simatupang, Y.M.A. 1999. Pengaruh Pemberian Bokashi Kotoran Ayam dan Bokashi Rumput Terhadap Beberapa Sifat Fisika Tanah Podsolik Merah Kuning Gajrug dan Pertumbuhan Tanaman Kedelai (Glycine max L. Merr) varietas Wilis. Skripsi. Fakultas Pertanian Intitut Pertanian Bogor.

Soverda,N., Rinaldy dan I. Susanti. 2008. Pengaruh Beberapa Macam Bokashi Terhadap Pertumbuhan dan Hasil Tanaman Tomat (Lycopersicum esculentum Mill.) Di Polybag. journal.unja.id/index.php/agrono mi/article/download/432/348.

Diakses tanggal 1 Desember 2013. 
Sumiarsi, N dan Setyowati, 2006. Pengaruh beberapa Media TerhadapPertumbuhan Bibit Eboni (Diospyros celebica Bakh). Melalui Perbanyakan biji . Biodipersitas. 7(3):260-263
Teruo, H. 1999. EM Technology. Indonesian Kyusei Nature Farming Societies. PT. Songgolangit Persada. Jakarta 